\title{
An approach using thin films as a predictive way to produce new bulk materials
}

\author{
M.T. Vieira ${ }^{\text {a,* }}$, A.S. Ramos ${ }^{\mathrm{a}}$, B. Trindade ${ }^{\mathrm{a}}$, J.V. Fernandes ${ }^{\mathrm{b}}$, M.F. Vieira ${ }^{\mathrm{c}}$ \\ a ICEMS, Departamento Engenharia Mecânica, Faculdade de Ciências e Tecnologia da Universidade de Coimbra, 3030 Coimbra, \\ Portugal \\ ${ }^{\mathrm{b}}$ CEMUC, Departamento Engenharia Mecânica, Faculdade de Ciências e Tecnologia da Universidade de Coimbra, 3030 Coimbra, \\ Portugal \\ ${ }^{\mathrm{c}}$ GMM / IMAT, Departamento Engenharia Metalurgica e Materiais, Faculdade de Engenharia do Porto, 4099 Porto, Portugal
}

\begin{abstract}
The aim of the present work is to produce (TiAl)-based films and characterise them in the as-deposited state and after several heat-treatment cycles with different holding times. The idea is to promote phase transformations of the films towards the intermetallic bulk materials. The structure and mechanical properties of binary films and films alloyed with silver were studied as a function of several heat treatment holding times at $600^{\circ} \mathrm{C}$. The room temperature stresses were also evaluated and show that during annealing the stresses move from a compressive to a tensile state. The $18 \mathrm{~h}$ heat treatment leads to a sharp hardening of the binary film thought as resulting from a fine precipitation. After $162 \mathrm{~h}$ heat treatment the grain size increases, but the intrinsic stresses compromise the ductility results obtained. (c) 2000 Elsevier Science B.V. All rights reserved.
\end{abstract}

Keywords: Titanium aluminides; Film/bulk materials; Mechanical properties

\section{Introduction}

Usually, literature highlights the use of thin films as functional, or even, structural materials with properties different from traditional materials. In fact, physical vapour deposition techniques (PVD) allow the manufacture of metastable structures, which are responsible for some unique properties not possible to obtain in conventional bulk materials [1].

In another perspective, deposition techniques, such as PVD, could be used to produce films whose properties might be extrapolated to bulk materials. Here the PVD (sputtering) is used as a screening technique as it enables to cover a wide range of compositions. The production of intermetallic materials by PVD is a prospective production process for future applications.

\footnotetext{
* Corresponding author.

E-mail address: teresa.vieira@mail.dem.uc.pt (M.T. Vieira).
}

Intermetallic compounds, such as $\gamma$-TiAl, are promising materials for space flight vehicles, turbine engines and high-performance automotive engines [2,3]. Although TiAl shows great potential for high temperature applications, it needs further investigation in order to overcome its lack of ductility [4,5]. A possible way to overcome the drawback of insufficient ductility is the addition of alloying elements. In fact, some authors found out that the ductility of $\gamma$-TiAl alloys can be improved by introducing 1-3\% of alloying elements such as V, Cr or Mn [5-8].

Intermetallic thin films with different compositions could be obtained by sputtering in order to optimise their mechanical properties, such as the material ductility. The optimised material composition will be tested in the form of bulk materials.

The aim of these investigations is the manufacturing of (TiAl)-based thin films and the extrapolation of the mechanical properties to intermetallic bulk compounds. The objective is to determine the heat treat- 
ment parameters to approach the microstructure of the films to the one obtained by foundry. Ti-Al and $\mathrm{Ti}-\mathrm{Al}-\mathrm{Ag}$ films were heat-treated with different holding times in order to decrease the residual stresses (thermal, intrinsic and misfit stresses) to approach the equilibrium structure. The effect of the heat treatment on the grain size was evaluated. The mechanical properties were determined by means of depth sensitive hardness testing and by a new tensile test procedure specially developed to determine the ductility of thin films.

\section{Experimental details}

$\mathrm{Ti}-\mathrm{Al}$ and $\mathrm{Ti}-\mathrm{Al}-\mathrm{Ag}$ thin films were co-deposited by d.c. magnetron sputtering on 304 austenitic stainless steel (AISI) substrates, as described elsewhere [9]. The samples were studied after heat treatment cycles at a temperature of $600^{\circ} \mathrm{C}$ during 1,18 and $162 \mathrm{~h}$ in a hydrogenated argon atmosphere. This temperature was chosen on the basis of previous works concerning the decomposition of the as-deposited structure $(\alpha-\mathrm{Ti}+$ (Al) solid solutions) to the intermetallic phase ( $\gamma$-TiAl) by means of differential scanning calorimetry [10]. Different heat treatment holding times were chosen to allow the formation of the equilibrium structure. To prevent the conversion of the coated steel microstructure higher treatment temperatures where not tolerable.

A new tensile test procedure has been developed to evaluate the ductility of the $\mathrm{Ti}-\mathrm{Al}$ and $\mathrm{Ti}-\mathrm{Al}-\mathrm{Ag}$ films produced. The AISI 304 steel tensile sample used has a special geometry, with a continuously variable crosssectional area, as shown in Fig. 1. With this particular geometry a continuous gradient of deformation was obtained across the sample. With beginning of plastic deformation $\left(\varepsilon_{B} \approx 0.01\right)$ in the maximum $(B)$ crosssectional area of the sample, the strain was close to the limit of homogeneous plastic strain of the substrate $\left(\varepsilon_{A} \approx 0.38\right)$ in the minimum $(A)$ cross-sectional area. To ensure the accuracy in the evaluation of the relatively low ductility of the $\mathrm{Ti}-\mathrm{Al}$ and $\mathrm{Ti}-\mathrm{Al}-\mathrm{Ag}$ films, the tensile tests were performed up to a deformation in A close to $\left(\varepsilon_{A}=0.10\right)$, being $B$ in the elastic domain $\left(\varepsilon_{B} \approx 0.00\right)$. The deformation gradient in the sample was determined measuring the deformation of 15 regions along the sample (each one 5-mm long). The deformation was measured using a travelling microscope, with an accuracy of $1 \mu \mathrm{m}$.

The films showed cracks where the strain imposed exceeds their ductility. Optical microscopy was used to define the regions where cracks appeared. The strain attained in this region characterises the ductility of the film.

A three-dimensional finite element code was used to

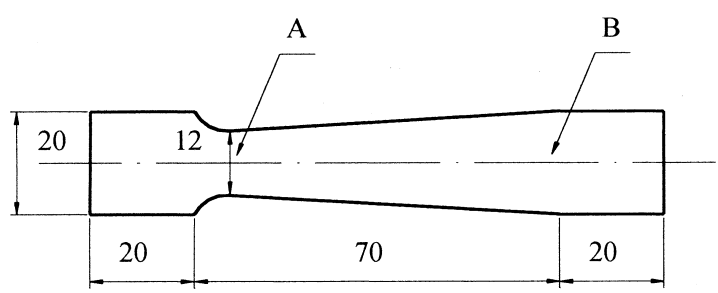

Fig. 1. Schematic representation of the tensile sample (dimensions in $\mathrm{mm})$.

simulate the deformation of this tensile sample [11]. The results have shown that the plastic strains in the film and in the substrate are similar. The stress tensor of the film at the observed regions was not influenced by the presence of the substrate, i.e. the values of redundant stress components (other than the tensile stress) were not significant. This led to the conclusion that the presence of the substrate does not influence the stress and strain conditions. These implications and the simplicity of the method show the advantage of this kind of samples to investigate the ductility of thin films.

\section{Results and discussion}

\subsection{Structure}

The deposited $\mathrm{Ti}-\mathrm{Al}$ films pointed at compositions close to 48 at.\% of aluminium. The silver content 1.4 at.\%, was introduced maintaining the aluminium content of the binary films. Previous investigations [10] showed that silver contents of 1.4 at.\% did not influence the ductility of the film after a 1-h heat treatment. The measured value is comparable to the data of the binary film. X-Ray diffraction (XRD) results of these samples showed that the as-deposited $\mathrm{Ti}-\mathrm{Al}$ film is formed by a two phase structure of titanium, $\alpha$ and/or $\alpha^{\prime}-\mathrm{Ti}$, and aluminium, (Al) [10]. This XRD is also representative of the as-deposited $\mathrm{Ti}-\mathrm{Al}-\mathrm{Ag}$ film. The desired $\gamma$-TiAl intermetallic structure was obtained after heat treatment at $600^{\circ} \mathrm{C}$ during $1 \mathrm{~h}$ for both, $\mathrm{Ti}-\mathrm{Al}$ and $\mathrm{Ti}-\mathrm{Al}-\mathrm{Ag}$ films. The silver content is too low to give rise to silver-rich phases detectable by XRD analysis. Transmission electron microscopy (TEM) images showed that the as-deposited binary film was formed by a very fine-grained structure corresponding to electron diffraction (ED) patterns indexed as $\alpha-\mathrm{Ti}$ and (Al) [10], confirming the XRD results. Concerning the annealed film, besides the $\gamma$-TiAl structure it was possible to identify a second phase indexed as $\gamma$-Ti (untransformed) or the intermetallic $\alpha_{2}-\mathrm{Ti}_{3} \mathrm{Al}$ phase. According to the $\mathrm{Ti}-\mathrm{Al}$ phase diagram at 48 at.\% aluminium content the equilibrium microstructure contains $\gamma-\mathrm{TiAl}+\alpha_{2}-\mathrm{Ti}_{3} \mathrm{Al}$ phases. Allowing with silver 


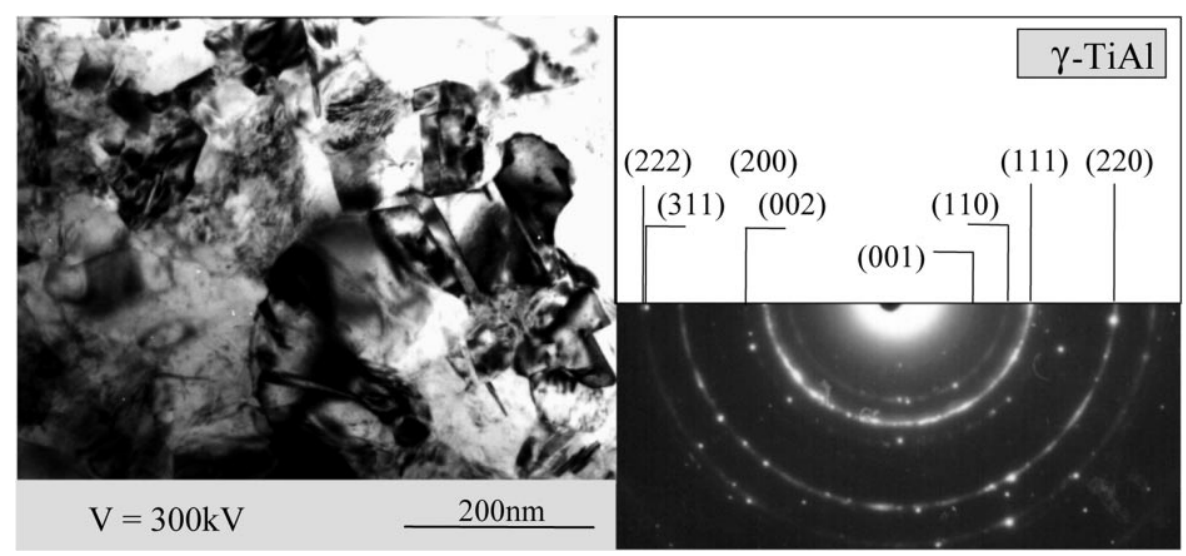

Fig. 2. TEM and ED micrographs of the heat-treated $\mathrm{Ti}-\mathrm{Al}-\mathrm{Ag}$ film $\left(600^{\circ} \mathrm{C} / 1 \mathrm{~h}\right)$.

results in suppression of the second phase, only $\gamma$-TiAl could be detected (Fig. 2).

The films annealed at 18 and $162 \mathrm{~h}$ were characterised by X-ray and TEM. The XRD diffractograms did not show structural modifications after heat treatment for a longer time and it was not possible to detect grain size variations. The TEM analysis enables detailed investigation. On the heat-treated $(162 \mathrm{~h})$ binary film it is possible to observe significant selective grainsize increases. In areas where the preferred secondary recrystallisation occurred, grain sizes of approximately $1 \mu \mathrm{m}$ could be detected (Fig. 3). For samples heat treated for $18 \mathrm{~h}$ no significantly larger grain sizes could be observed by TEM compared to films annealed for 1 h. In comparison, the large grain-size bulk microstructure is presented in Fig. 4 as an optical image of a binary TiAl bulk sample $(d \approx 100 \mu \mathrm{m})$. The grain size evolution, function of the heat treatment holding time, of the films alloyed with silver is similar to the binary films one.

\subsection{Mechanical properties}

Fig. 5 shows the hardness and ductility results as function of the heat treatment holding time. Firstly, it is interesting to note that no influence on the hardness and ductility with silver content could be observed for the films heat-treated at $600^{\circ} \mathrm{C}$ for $1 \mathrm{~h}$, which is the starting point for longer heat treatment investigations. For this point, hardness tests using different loads were conducted in order to determine Young's modulus [12] of the TiAl intermetallic film (220 GPa). The value obtained is higher than Young's modulus of cast TiAl, also determined by ultramicrohardness testing (165 GPa). This is a typical result of the sputtering process [13] that is responsible for the high level of intrinsic stresses of the film compared with the bulk material.

Concerning the hardness it is observed an increase of the as-deposited $\mathrm{Ti}-\mathrm{Al}$ structure up to the $18 \mathrm{~h}$ heat treatment, for which a high hardness value is achieved.

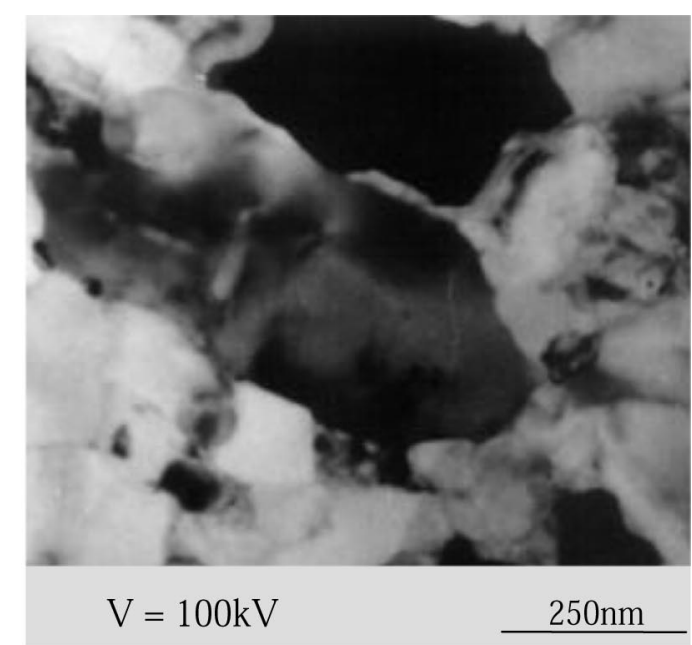

(b)

(a)

Fig. 3. TEM images of the TiAl film heat treated during $18 \mathrm{~h}$ (a) and $162 \mathrm{~h}$ (b). 


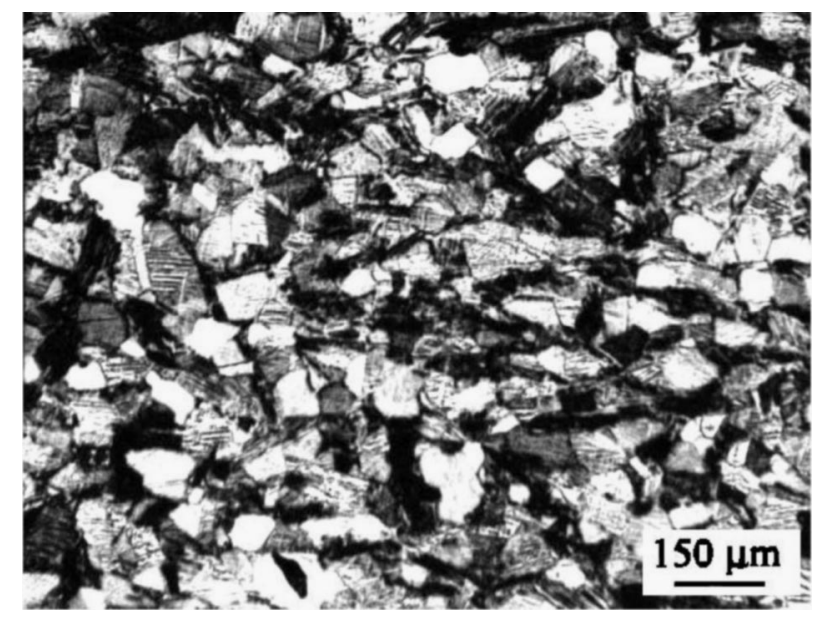

Fig. 4. Optical microscopy picture of a TiAl bulk sample.

The hardening effect of the binary films can be explained by a fine precipitation during the $18 \mathrm{~h}$ annealing of some untransformed material that might remain after $1 \mathrm{~h}$ heat treatment, as the TEM analysis suggests. As expected, the precipitates become incoherent due to their growing during the $162 \mathrm{~h}$ heat treatment at $600^{\circ} \mathrm{C}$ and are responsible for a small hardness decrease. The introduction of silver leads to a decreasing curve with the heat treatment holding time as a result of the observed grain size increase. In the presence of silver, the hardening effect decreases, probably because, as this element favours the transition $\alpha-\mathrm{Ti}+(\mathrm{Al}) \rightarrow(\gamma-$ $\mathrm{TiAl}$ [10], after $1 \mathrm{~h}$ there is no untransformed material to precipitate. In comparison to bulk materials, the heat-treated films show significantly increase of hardness, which may be due to the sputtering process. The ultramicrohardness tests reveal a 4-5 GPa hardness value for cast TiAl (48 at.\% of aluminium), which slightly increases with the introduction of 1 at.\% of silver.

To extrapolate the films' ductility results to bulk materials it is necessary to eliminate the residual

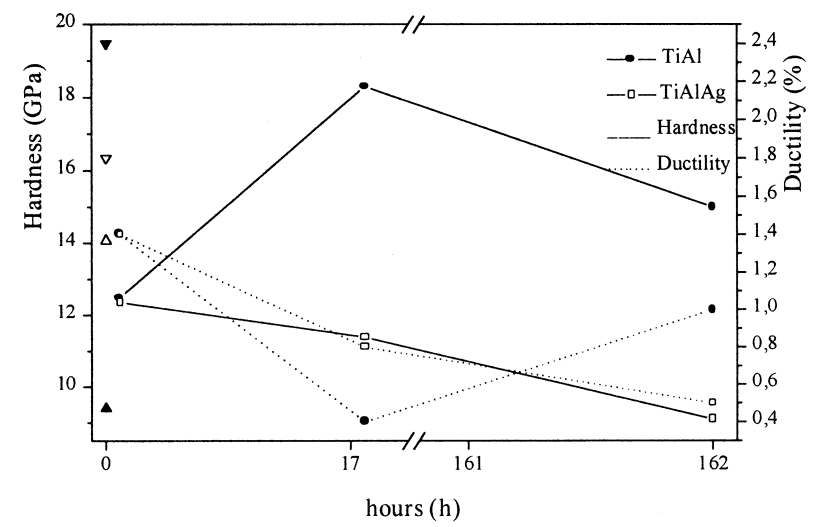

Fig. 5. Hardness and ductility of TiAl and TiAlAg films as function of the annealing holding time. As-deposited Ti-Al hardness ( $\mathbf{\Delta}$ ); as-deposited $\mathrm{Ti}-\mathrm{Al}-\mathrm{Ag}$ hardness $(\Delta)$ as-deposited $\mathrm{Ti}-\mathrm{Al}$ ductility $(\nabla)$; as-deposited $\mathrm{Ti}-\mathrm{Al}-\mathrm{Ag}$ ductility $(\nabla)$. stresses of the films, since the existence of these stresses leads to apparent ductility values. In fact, the tension value where the appearance of the first cracks could be observed highly depends on the initial stress-state. The initial stress-state will influence the obtained ductility results. Thus, the initial compressive state $(\sigma \approx-0.5$ $\mathrm{GPa}$ ), determined by beam laser bending analysis [14], explains the higher ductility results of the as-deposited films. The stress-state also influences the development of the ductility curve of the annealed films with the holding time at $600^{\circ} \mathrm{C}$. The heat treatment to obtain the intermetallic structure leads to a tensile state whose value increases up to the $18 \mathrm{~h}$ holding time. The transition from a compressive to a tensile state by annealing, which was also observed by Chinmulgund et al. [15], results from a decrease of the specific volume $\left(V_{\gamma \text {-TiAl }}<V_{\alpha \text {-Ti+(AI) }}\right)$. This effect can only be avoided if a $\gamma$-TiAl composite target is used instead of two targets (titanium and aluminium) allowing obtaining intermetallic as-deposited films. In the case of the binary film the sharp hardening observed at $18 \mathrm{~h}$ heat treatment reinforces the stress effect and is responsible for the low ductility value obtained compared with the Ti-Al-Ag film whose tensile stress is higher $(\sigma \approx+1.7$ $\mathrm{GPa}$ against $\sigma \approx+1.2 \mathrm{GPa}$ ). Here, the hardness effect superimposes the stresses; as it is known, an increase in hardness leads to a decrease of the ductility.

\section{Conclusions}

As a first approach to predict intermetallic bulk materials properties the results obtained for the investigation of thin films mainly aimed at understanding the influence of structure and intrinsic stresses on the hardness and ductility evaluated after heat treatments performed for several holding times.

It was found out that the grain size only increases towards the bulk microstructure with long heat treatment holding times $(162 \mathrm{~h})$. It should also be noted that the ductility values of the $\mathrm{Ti}-\mathrm{Al}$ and $\mathrm{Ti}-\mathrm{Al}-\mathrm{Ag}$ films result from the combined effect of microstructure and stress-state. The investigations showed an undesired transition from a compressive to a tensile state after annealing at temperature of $600^{\circ} \mathrm{C}$. This effect was attributed to the disposal of two targets which led to a two solid solution as-deposited structure $[\alpha-\mathrm{Ti}+(\mathrm{Al})]$ and to a volume decrease during the formation of the intermetallic structure. Long heat treatment holding times did not contribute to the intended ductility increase.

\section{Acknowledgements}

This work was supported by Fundação para a Ciência e Tecnologia, BD/3623. 


\section{References}

[1] H. Holleck, Surf. Coat. Technol. 36 (1988) 151.

[2] C. Suryanarayana, F.H. Froes, Mater. Sci. Eng. A179/180 (1994) 108.

[3] E.L. Hall, S.C. Huang, J. Mater. Res. 4 (3) (1989) 595.

[4] F.H. Froes, C. Suryanarayana, D.J. Eliezer, J. Mater. Sci. 27 (1992) 5113.

[5] Y.G. Li, M.H. Loretto, Acta Metall. Mater. 42 (1994) 2009.

[6] M. Morinaga, J. Saito, N. Yukawa, H. Adachi, Acta Metall. Mater. 38 (1) (1990) 25.

[7] S.C. Huang, J.C. Chesnutt in Intermetallic Compounds Principles and Practice, vol.2, in: J.H. Westbrook, R.L. Fleisher, (Eds.), USA, 1995.

[8] T. Kawabata, H. Fukai, O. Izumi, Acta Metall. Mater. 46 (6) (1998) 2185.

[9] M.T. Vieira, B. Trindade, A.S. Ramos, C. Coelho, Proceedings of the Eurmat '98, Vol. 1, Portugal, 1998, pp. 651-659.
[10] C. Coelho, A.S. Ramos, B. Trindade, M.T. Vieira, J.V. Fernandes, M.F. Vieira, Surf. Coat. Technol. 120/121 (1999) 297.

[11] J.M. Antunes, L.F. Menezes, J.V. Fernandes, Proceedings of the Second Esaform Conference on Material Forming: Experimental Investigations, Physical Approaches, Numerical Modelling and Engineering Case Studies, Guimarães, Portugal, pp. 183-186.

[12] J. Mencík, D. Munz, E. Quandt, E.R. Weppelmann, M.V. Swain, J. Mater. Res. 12 (9) (1997) 2475.

[13] J.M. Cirne, A. Amaro, N. Rilo, R.P. Leal, M.T. Vieira, M. Vaz, J.F. Silva Gomes, Identification of the Young Modulus of The Tungsten Using the Holographic Interferometry and the Finite Element Methods, Proceedings of Integrity, Reliability and Failure-International Conference, Porto, Portugal, 1999.

[14] P.A. Flinn, MRS Symposium Proceedings, 130 (1989) 41.

[15] M. Chinmulgund, R.B. Inturi, J.A. Barnard, Thin Solid Films 270 (1995) 260. 